\title{
RESEARCH
}

Open Access

\section{"If I had known, I would have applied": poor communication, job dissatisfaction, and attrition of rural health workers in Sierra Leone}

Vijay Narayan ${ }^{1 *} \mathbb{D}$, Grace John-Stewart ${ }^{1}, G^{\prime}$ eorge Gage ${ }^{2}$ and Gabrielle O'Malley ${ }^{1}$

\begin{abstract}
Background: Sierra Leone's health outcomes rank among the worst in the world. A major challenge is the shortage of primary healthcare workers (HCWs) in rural areas due to especially high rates of attrition. This study was undertaken to determine the drivers of job dissatisfaction and poor retention among Sierra Leone's rural HCWs.

Methods: Interviews were conducted with 58 rural and 32 urban primary HCWs in Sierra Leone's public health sector, complemented by key informant discussions and review of national policy documents. HCW interviews included (1) semi-structured discussion, (2) questionnaire, (3) card sort about HCW priorities, and (4) free-listing of most pressing challenges and needs. Sampling for HCW interviews was stratified purposive, emphasizing rural HCWs.

Results: Among $90 \mathrm{HCWs}$ interviewed, 67\% were dissatisfied with their jobs (71\% rural vs $52 \%$ urban) and 61\% intended to leave their post (75\% rural vs 38\% urban). While working and living conditions and remuneration were significant factors, a major reason for rural HCW disenchantment was their inability to access worker rights, benefits, and advancement opportunities. This was caused by HCWs' lack of knowledge about human resource (HR) policies and procedures, as well as ambiguity in many policies and inequitable implementation. HCWs reported feeling neglected and marginalized and perceived a lack of transparency. These issues can be attributed to the absence of systems for regular two-way communication between the Ministry of Health and HCWs; lack of official national documents with up-to-date, clear HR policies and procedures for HCWs; pay statements that do not provide a breakdown of financial allowances and withholdings; and lack of HCW induction.

Conclusions: HCWs in Sierra Leone lacked accurate information about entitlements, policies, and procedures, and this was a driver of rural HCW job dissatisfaction and attrition. System-oriented, low-cost initiatives can address these underlying structural causes in Sierra Leone. These issues likely apply to other countries facing HCW retention challenges and should be considered in development of global HCW retention strategies.
\end{abstract}

Keywords: Sierra Leone, Health workforce retention, Distribution, Job satisfaction, Communication, Policies, Employee benefits, Healthcare worker, Motivation, Rural and remote areas

\footnotetext{
* Correspondence: vijay.narayan.5@gmail.com

'Department of Global Health, University of Washington, Seattle, United

States of America

Full list of author information is available at the end of the article
}

(c) The Author(s). 2018 Open Access This article is distributed under the terms of the Creative Commons Attribution 4.0 International License (http://creativecommons.org/licenses/by/4.0/), which permits unrestricted use, distribution, and reproduction in any medium, provided you give appropriate credit to the original author(s) and the source, provide a link to the Creative Commons license, and indicate if changes were made. The Creative Commons Public Domain Dedication waiver (http://creativecommons.org/publicdomain/zero/1.0/) applies to the data made available in this article, unless otherwise stated. 


\section{Backround}

The severe shortage of healthcare workers (HCWs) in rural communities of low-income countries is a global crisis, driving poor health outcomes by reducing access to medical care and quality of health service delivery [1-4]. In the many sub-Saharan African countries with majority rural populations, poor retention of HCWs in rural areas is especially problematic $[5,6]$.

The situation is especially stark in Sierra Leone, whose health indices rank among the very worst in the world in terms of its maternal, infant, and under-5 mortality rates, as well as overall life expectancy $[7,8]$. Devastating Ebola and cholera epidemics in recent years have exacerbated Sierra Leone's health crisis [9, 10].

Despite $63 \%$ of Sierra Leone's population residing in rural areas, only $33 \%$ of the country's health professionals work at rural health posts $[11,12]$. Many HCWs in Sierra Leone refuse their rural postings, and attrition rates among rural HCWs are high $[13,14]$. At the same time, government initiatives-such as the Free Healthcare Initiative and removal of user fees for malaria and tuberculosis care-have increased patient demand [15]. With insufficient numbers of well-equipped and motivated HCWs in rural areas, Sierra Leone's health system cannot meet the essential health needs of the majority rural population. Adding to this challenge, the country has very few medical doctors (only 0.3 per 10000 population), and the few doctors work exclusively in urban or peri-urban areas [16, 17]. The population largely depends on the government for health services: public health facilities provide $70 \%$ of the services in the country, while private and mission facilities provide the remaining 30\% [12]. See Additional file 1 for an overview of Sierra Leone's health system.
Reasons for rural attrition and mal-distribution in low-income countries have been identified in numerous studies and reviews. Commonly cited factors affecting rural job dissatisfaction include working and living conditions, salary and financial allowances, access to career development opportunities and promotion pathways, supervision and management at the health facility, support systems, and family considerations [18-24]. According to research by Wurie et al., many of these factors contribute to job dissatisfaction among Sierra Leone's rural health workers [25].

What has not been well documented, however, is how lack of $\mathrm{HCW}$ knowledge about human resource (HR) policies/procedures and poor communication between the government and its HCWs negatively impacts HCW retention in rural areas. This study examines how these knowledge and communication dynamics contribute to the demotivation of rural health workers and proposes recommendations for strengthening $\mathrm{HCW}$ capacity to navigate the human resources for health system of which they are an essential part.

\section{Methods \\ Study design}

Data for this mixed-method cross-sectional study were collected in Sierra Leone in 2014-2015. Data were collected via in-depth interviews with primary HCWs at public-sector health facilities throughout the country $(N=$ 90), key informant discussions with governmental and non-government stakeholders $(N=37)$, and a review of policy documents and electronic data tools (Fig. 1). Data collection took place prior to Sierra Leone's Ebola outbreak.

Key informant discussions were held with district and national government health officials, managers from non-governmental organizations (NGOs), staff from

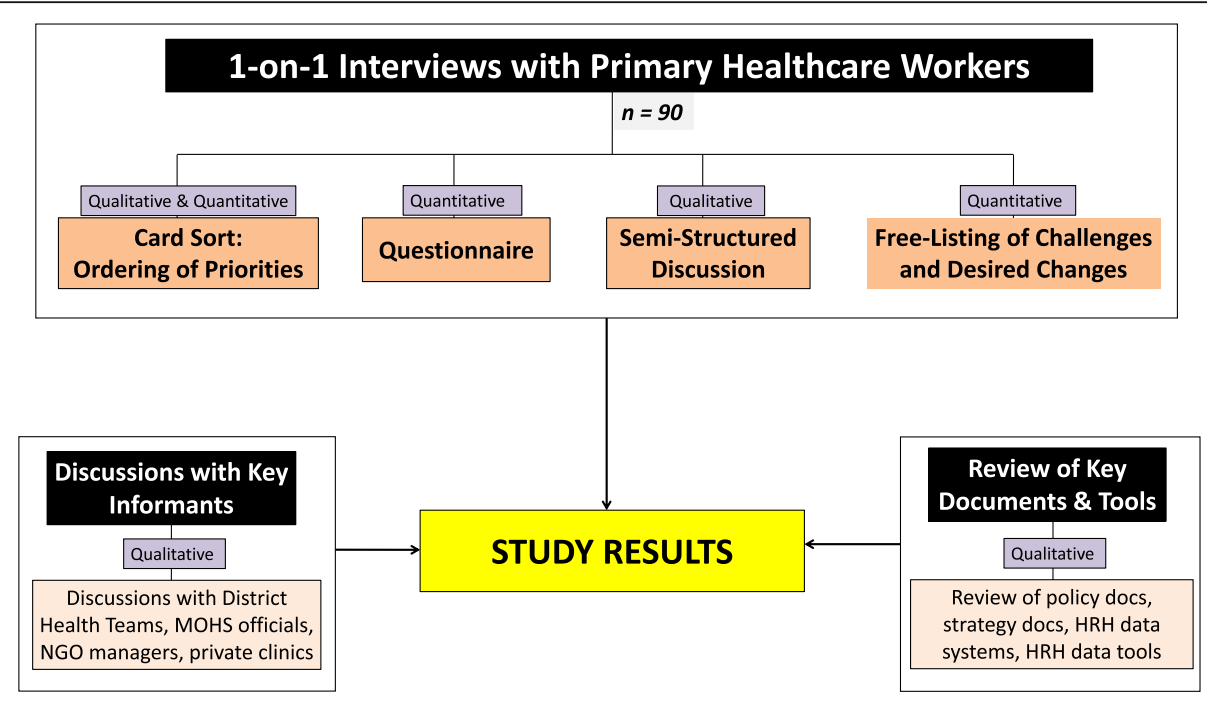

Fig. 1 Design of health workforce retention study. Abbrev: MOHS = Ministry of Health and Sanitation, HRH = Human Resources for Health 
mission and private health facilities, and other relevant stakeholders. Discussions sought to shed light on systemic gaps undermining health workforce retention.

$\mathrm{HCW}$ interviews elicited qualitative and quantitative data about their individual professional and personal experiences, challenges, factors influencing their intentions to stay or leave a health posting, and types of changes that would encourage them to stay at their current posts. Interviews included four components: a 30-question survey adapted from previous studies conducted in Uganda and Kenya [26], a semi-structured discussion in which the health workers described their personal experiences, a listing exercise where health workers were asked to free-list in order of priority a maximum of seven of their most important workplace challenges and seven things they would want the government to do to increase their desire to stay at their current posting, and a card sort activity in which health care workers were asked to rank-order 13 cards depicting factors affecting job satisfaction frequently referenced in the general literature. An additional file lists the 13 factors in the card sort and describes the method (see Additional file 2).

Interviews were conducted at the health facility in a private place in the language that was most comfortable to the HCW (English, Krio, or both). No personal identifiers were documented, and written consent was obtained before the interview. Interviews lasted approximately $1.5 \mathrm{~h}$ and were audio-recorded. The card sort, free lists, and survey responses were documented on a data collection tool.

The document review provided additional context to the findings from the $\mathrm{HCW}$ interviews. Reviewed documents included the Civil Service Code of Rules and Regulations, Human Resources for Health Policy, Human Resources for Health (HRH) Strategic Plan, Essential Healthcare Package, Primary Healthcare Handbook, and National Health Training Plan. The review also included the electronic and paper tools used to collect and manage $\mathrm{HRH}$ data at the district and national levels.

\section{Sampling and participant selection}

We used maximum variation sampling and purposively sampled individuals across five strata, including type of setting, health facility level, health worker cadre, geographical region and district, and supervisory status (Table 1). Facilities were selected with the help of district health management teams (DHMT), and in each district, study investigators prioritized the most "hard-to-reach" health facilities, while attaining a balance of cadres and facility levels. Rural health facilities were oversampled because the study's primary focus was the rural workforce. The study achieved regional balance, including all
Table 1 Sampling strata for healthcare worker interviews

\begin{tabular}{l} 
Purposive sampling: strata \\
Type of setting \\
Urban \\
Peri-urban \\
Rural \\
Supervisory status \\
Supervisor \\
Non-supervisor \\
Facility level \\
Hospital \\
Community health center (CHC) \\
Community health post (CHP) \\
Maternal-child health post (MCHP) \\
Cadre \\
State-registered nurse (SRN) \\
State-enrolled community health nurse (SECHN) \\
Community health officer (CHO) \\
Community health assistant (CHA) \\
Maternal child health aide (MCHA) \\
Region and district \\
All 4 regions (North, South, East, West) \\
Kenema, Bo, Bombali, Port Loko, Kambia, Koinadugu, Tonkolili) \\
\hline
\end{tabular}

13 districts and 6-8 chiefdoms within each district. Health worker interviews included all cadres involved in primary healthcare at public-sector health facilities (state-registered nurse (SRN), state-enrolled community health nurse (SECHN), community health officer $(\mathrm{CHO})$, community health assistant (CHA), maternal child health aide (MCHA)).

Only one HCW was interviewed at any single rural facility, and a maximum of two HCWs were interviewed at any hospital. Upon reaching each facility, interviewers explained the study to the site supervisor and the chosen $\mathrm{HCW}$, who was then asked if he/she wanted to participate. No HCW refused to participate in the study.

Convenience sampling was used for selection of key informants. For the review of key documents and tools, sampling was inclusive of all accessible national documents that were relevant to the health workforce and delivery of primary healthcare services.

Given our sampling method and sample size, our study findings are not generalizable to the entire health workforce. Rather, our intention was to provide an in-depth examination and description of dissatisfaction and demotivation among a purposive sample of health care workers so as to better inform policies for improving health workforce retention in Sierra Leone. 


\section{Data analysis}

Audio recordings for the health worker interviews were translated into English where necessary and transcribed. Interview transcripts, national documents, and photos taken at health facilities were imported and managed in Atlas.Ti. We used thematic analysis to generate a nuanced description of health worker perspectives and experiences within the context of facility infrastructure and national policies [27, 28]. Inductive analysis was used to develop primary and axial codes which formed an initial code book. Codes were then modified and refined through "test-coding" of several transcripts. The resulting final codebook was then used with all transcripts. Coded text and images from all data sources were analyzed and synthesized to identify key themes in answer to the research questions.

Preliminary results were shared with co-researchers in country, and their feedback was incorporated into the analysis. Quantitative data from card sorts, free-list rankings of challenges and desired interventions, and questionnaires were analyzed using Microsoft Excel and SPSS. The data analyses from the different methods were synthesized and triangulated [29].

\section{Ethical considerations}

Ethical approval for the study was obtained from the Sierra Leone Research and Ethics Committee, as well as the University of Washington Institutional Review Board.

\section{Results}

Out of 90 interviewed HCWs, 58 were working in rural facilities and 32 were in urban or peri-urban facilities (Table 2).

Of 90 interviewed $\mathrm{HCWs}, 61 \%$ reported that they intended to leave their current posting within 1 year. Rates of "intention to leave" were higher in rural than urban workers (75\% vs $38 \%$, respectively). Rural HCWs reported lower job satisfaction than urban HCWs (2.61 vs. 3.31 on a 5-point Likert scale). Substandard living/ working conditions and remuneration gaps were significant factors affecting intention to leave among rural HCWs. Most rural HCWs in this study were living and working with inadequate or no housing, electricity, clean water, and means for basic transport, while simultaneously lacking essential equipment needed to do their jobs effectively. Many rural HCWs were not receiving their salaries or financial allowances. Figure 2 shows the top five most pressing challenges affecting job satisfaction free-listed by the interviewed rural HCWs $(n=58)$.

Among interviewed urban and peri-urban HCWs, the most pressing challenges reported were lack of housing quarters, inadequate medical supplies and stock out of medicines at health facilities, low salary, and lack of career advancement opportunities.
Table 2 Sample strata breakdown and study participant characteristics

\begin{tabular}{|c|c|c|}
\hline \multicolumn{3}{|l|}{ Sample strata breakdown } \\
\hline \multicolumn{3}{|l|}{ Type of setting } \\
\hline Rural facilities & 58 & $64 \%$ \\
\hline Urban and peri-urban facilities & 32 & $36 \%$ \\
\hline Total & 90 & \\
\hline \multicolumn{3}{|l|}{ Health facility level } \\
\hline Hospital & 29 & $32 \%$ \\
\hline Community health center (CHC) & 27 & $30 \%$ \\
\hline Community health post (CHP) & 20 & $22 \%$ \\
\hline $\mathrm{MCH}$ post (MCHP) & 14 & $16 \%$ \\
\hline Total & 90 & \\
\hline \multicolumn{3}{|l|}{ Cadre of health worker } \\
\hline SRN (state-registered nurse) & 14 & $16 \%$ \\
\hline SECHN (state-enrolled community nurse) & 25 & $28 \%$ \\
\hline $\mathrm{CHO}$ (community health officer) & 16 & $18 \%$ \\
\hline CHA (community health assistant) & 10 & $11 \%$ \\
\hline MCHA (maternal-child health aide) & 25 & $28 \%$ \\
\hline Total & 90 & \\
\hline \multicolumn{3}{|l|}{ Region of health worker } \\
\hline North & 28 & $31 \%$ \\
\hline South & 25 & $28 \%$ \\
\hline East & 23 & $26 \%$ \\
\hline West (Freetown) & 14 & $16 \%$ \\
\hline Total & 90 & \\
\hline \multicolumn{3}{|l|}{ Participant characteristics } \\
\hline \multicolumn{3}{|l|}{ Age of health workers } \\
\hline Mean age & & 40.1 years \\
\hline Median age & & 41.0 years \\
\hline \multicolumn{3}{|l|}{ Gender of health workers } \\
\hline Female & 57 & $37 \%$ \\
\hline Male & 33 & $63 \%$ \\
\hline Total & 90 & \\
\hline \multicolumn{3}{|l|}{ Region of origin } \\
\hline Working in region of birth & 50 & $56 \%$ \\
\hline Working in another region & 40 & $44 \%$ \\
\hline Total & 90 & \\
\hline \multicolumn{3}{|l|}{ Professional work experience } \\
\hline $0-2$ years & 5 & $5 \%$ \\
\hline $2-5$ years & 27 & $30 \%$ \\
\hline $5-10$ years & 25 & $28 \%$ \\
\hline $11-15$ years & 14 & $16 \%$ \\
\hline$>15$ years & 19 & $21 \%$ \\
\hline Total & 90 & \\
\hline Mean \# years working (total) & & 9.9 years \\
\hline Mean \# years at current post & & 2.7 years \\
\hline
\end{tabular}




\section{Top Five "Most Pressing Challenges at Current Post" Rural Workers Only ( $n=58)$}

Number of Rural Health Workers who Listed the Challenge

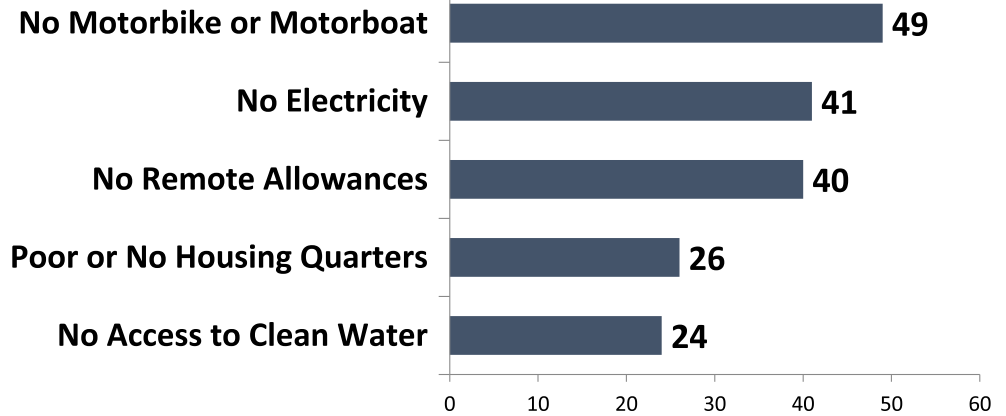

Fig. 2 Top five "most pressing challenges at current post" listed by rural health workers $(n=58)$

However, beyond the lack of financial and material support, we found a major underlying reason for $\mathrm{HCW}$ disenchantment was HCWs' lack of knowledge and information about their entitlements as civil servants, national human resource policies (e.g., eligibility criteria for career advancement opportunities), and proper procedures for obtaining benefits (such as annual leave or medical care). This was compounded by the ambiguity of many $\mathrm{HR}$ policies pertaining to $\mathrm{HCW}$ opportunities and rights. The information and communication gaps disproportionately affected rural HCWs due to their isolation and distance from the central government. However, despite greater proximity and access to the regional or central government, urban HCWs were also detrimentally affected since they were often getting unreliable or wrong information.

Lack of knowledge has prevented health workers from accessing their employee rights

Lack of accurate knowledge about policies and procedures prevented many HCWs from benefitting from career advancement opportunities, being absorbed onto the national payroll or being promoted, receiving paid annual leave, going to the right people/places in the government for resolution of professional problems, and so on. HCWs lacked awareness of policy and programming changes at the national level that affected their wellbeing, such as the shift to a new promotion system (Scheme of Service). As one rural HCW commented,

They don't give us any information, so how are we to plan our lives and get the government opportunities? We don't know what to do to get this opportunity, or who to go to for fixing this problem. I don't know why they made this or that decision. (SECHN 34)

HCWs are entitled to paid annual vacation leave of 1 month. However, as shown in Table 3, only 43\% of the interviewed HCWs knew about this policy, only $29 \%$ knew the steps to apply for it, and consequently only $16 \%$ reported ever receiving an annual leave allowance.

Table 3 Health worker knowledge and utilization of "annual leave" entitlement

\begin{tabular}{|c|c|c|c|}
\hline Knows about annual leave a & that it includes financial "allowance" (extra month of salary) & 39 out of 90 & $43 \%$ \\
\hline & Freetown city (western region) & 14 out of 14 & $100 \%$ \\
\hline & 12 upcountry districts (north, south, and east regions) & 25 out of 76 & $33 \%$ \\
\hline Knows process for applying & annual leave & 26 out of 90 & $29 \%$ \\
\hline & Freetown city (western region) & 13 out of 14 & $93 \%$ \\
\hline & 12 upcountry districts (north, south, and east regions) & 13 out of 76 & $16 \%$ \\
\hline Received "leave allowance" & & 14 out of 90 & $16 \%$ \\
\hline & Freetown city (western region) & 13 out of 14 & $93 \%$ \\
\hline & 12 upcountry districts (north, south, and east regions) & 1 out of 76 & $2 \%$ \\
\hline
\end{tabular}


Further, only $2 \%$ of upcountry workers benefitted from the allowance, compared to $93 \%$ of Freetown workers. According to a rural HCW,

I never even applied for [annual] leave because my family is here and I have nowhere else I would go.

But if I had known about the extra month of salary, I would have applied every year. We need that. We have earned that allowance. (SECHN-Midwife 75)

\section{Absence of accurate information fuels conjecture, speculation, and disenchantment}

When HCWs lack information, they often make assumptions which are inaccurate. Uninformed conjecture can lead to disenchantment with the government that may be unwarranted. For example, prior to 2013, the government had a provision called "Study Leave with Pay" which enables HCWs to advance their careers by continuing to pay them while they attend school. In 2013, the government stopped the "Study Leave with Pay" provision. However, the information about halting the policy and the rationale was not effectively communicated to HCWs. Only 9\% of HCWs (8/90) knew about the policy change. One rural $\mathrm{MCH}$ aide had heard from colleagues that only the $\mathrm{MCH}$ aides were being denied career advancement opportunities. Since the $\mathrm{MCH}$ aide had not received any official information, she and her colleagues interpreted the measure as marginalization of their entire cadre:

Every day, the government sends CHOs, SECHNs, midwives, and other cadres to study. The government never thinks of that for us- we the MCH Aides. I don't know why they don't want us to advance. The government doesn't respect us, even when we do so much of the work. (MCH Aide 27)

The $\mathrm{MCH}$ aide was unhappy that she and her colleagues were being ignored as compared to other cadres. This belief, which stemmed from lack of knowledge and inaccurate assumptions, was the primary reason given by the interviewed $\mathrm{HCW}$ for her overall job dissatisfaction.

\section{Inability to know the breakdown of "composite salary" has disempowered HCWs}

HCWs only see the total amount of money placed in their bank account every month. They do not receive a statement showing if and what amounts of money they are receiving for housing, medical risk, and transport, as well as what is withheld for social security and taxes. A rural HCW with no housing quarters expressed unhappiness that the government was not providing additional funds to compensate for his high rent costs. Since he did not have a disaggregated pay statement, he did not know if the issue to redress was (1) the lack of housing allowance, or (2) the housing allowance is provided but too small, or (3) the housing allowance is sufficient but the "base salary" is too small. He explained this challenge:

I have never seen my pay breakdown. They just send whole salary amount into my account. How can I know if I get housing allowance? I don't even know 'this is for what', or 'that is for what'. That info has never been given to anybody. So I don't know which [thing] is the problem. (CHO 02)

"Remote station allowances" were supposed to be provided as an incentive to $\mathrm{HCW}$ s to work in rural areas. Many interviewed HCWs reported not receiving these allowances for at least the previous 1 year. However, officials in several districts said the HCWs were receiving the allowances but had no way of knowing because their pay statements were not disaggregated. National-level officials later confirmed that the remote allowances had indeed stopped. This example shows how aggregated pay statements have been so problematic: HCWs had no recourse because they were told that they were receiving the remote allowances, but could not access the information which would have enabled them to confirm or refute that assertion.

\section{Lack of clarity in policies has led to confusion and inconsistent implementation}

In numerous areas pertaining to $\mathrm{HCW}$ benefits, there was no clear policy from the Ministry of Health and Sanitation (MOHS) HRH Directorate or Human Resource Management Office (HRMO). In other cases, there was an official policy position at high levels in the MOHS, but it had not been disseminated to the key national or district officials involved in implementation; this was especially the case when it involved changes to existing policies and programs.

We found confusion and inconsistency among health workers, MOHS and district health officials, HRMO staff, and other relevant stakeholders in the policy for provision of medical care for HCWs and their families, the eligibility criteria for "study leave with pay" and current status of that benefit, the status of remote allowances and which health workers were eligible, and the exact procedures HCWs should follow for absorption onto payroll and salary promotion, among many others. The only reference document for these policies was the Civil Service Code [30], which articulates the policies and entitlements for civil servants in Sierra Leone. However, few HCWs were aware of the Civil Service Code, and even fewer HCWs had obtained a copy of the Civil 
Service Code since its printing expense made it hard to access.

While an important document for HCWs to have, many of the Civil Service Code's provisions are non-specific or ambiguous, and outdated since the Code was created 10 years earlier and meant to be broad so it could apply to all civil servants for an extended time period. For example, one provision in the Code reads that "civil servants shall receive a medical care allowance to be determined from time to time." Based on this wording, HCWs do not know if they are supposed to be provided with this allowance at the current time, and in what amount. The Civil Service Code also does not reflect programming changes such as the switch to a different performance appraisal system for MOHS staff, or changes in implementation of a policy due to changes in MOHS funding allocation (e.g., halting of remote allowances).

The lack of a national policy document describing how the Civil Service Code's provisions specifically apply to MOHS staff in the current time period has prevented clear understanding and interpretation of policies at all levels, while reducing transparency. According to a district health official,

Many things are unclear to the [health facility] staff and even ourselves here at the district office. In Freetown they need to harmonize the Civil Code with actual policies to make official Ministry of Health policy guidelines. (DHMT staff, Outlying district)

The policy ambiguity led to inconsistent and often inequitable implementation on the ground: some HCWs received benefits and opportunities while others did not. This is highlighted by the example of medical care coverage for HCWs and their families. Figure 3 shows the discrepancy between how HCWs interpreted the medical care policy and how they actually accessed medical care: some HCWs received free care and medications, others received either one or the other, while most paid out of pocket for all care and treatment. Often HCWs just did what their colleagues were doing or what they had heard from other people. Some asked the

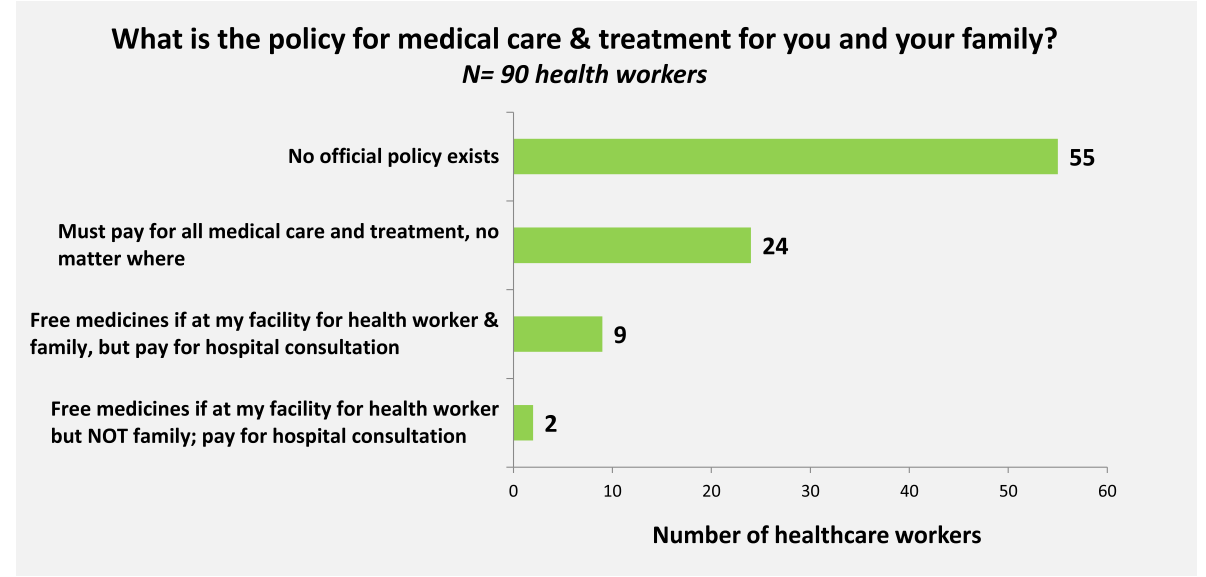

Translates to

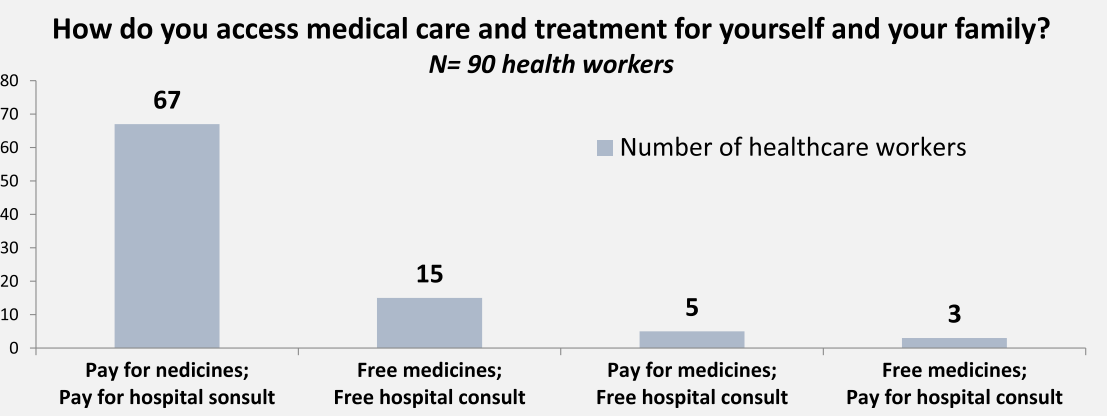

Fig. 3 Policy knowledge versus policy implementation among health workers. Two graphs showing an example of policy ambiguity translated to inequitable policy implementation. Top graph shows health worker understanding of the policy regarding medical care provision for themselves and their families. Bottom graph shows how health workers actually accessed medical care 
district or officials, but received conflicting information. One rural HCW explained:

To be honest, when me or my wife are sick, I use the medicines here [at the facility]. I do not know if that is recommended. No one at the district office knows when I ask, and sometimes I think it is [a] legal risk. (SECHN 17)

\section{Ineffective communication channels between government and health workers drive the knowledge and information gaps}

Key information from the central government rarely reached HCWs, especially in outlying districts and remote areas. Communications from the national level about policy changes were ad hoc rather than part of an organized system where information is regularly conveyed between central government, districts, and HCWs. Further, there were no tracking mechanisms to ensure that the information reached its intended recipients. According to an official from an outlying district,

We find out new policies and things happening in the Ministry [of Health] sometimes from written memos they send, or when a colleague is in Freetown, or from our health staffs who got it from friends.

Sometimes not at all. (DHMT staff, Outlying district)

There was also no systematic feedback channel for HCWs to voice their concerns and questions to the district and central government. As the HCW in-charge of a rural facility explained,

I carry to the district our challenges and things we want to know, but I don't get the information. The [district] says they are trying and communicating to Freetown. But no response reaches to us. (CHA 50)

The absence of an effective two-way communication channel exacerbated the confusion among HCWs about the "study leave with pay" and "remote allowance" policies, and made it difficult for HCWs to rectify individual HR issues such as not being absorbed onto the national payroll.

Compounding the lack of regular communication channels was the absence of induction: new HCWs were never formally oriented to the MOHS' policies and procedures before initial deployment. One rural HCW commented:

If only they convene all the staffs together in the district or Freetown and tell [us] all the policies in effect, we can know how to apply for scholarships or get our problems fixed like this broken [maternity] bed here. (CHO 57)

\section{Discussion}

We found that many primary HCWs in rural Sierra Leone were dissatisfied with their jobs and intended to leave their post within 1 year. Consistent with a prior analysis in Sierra Leone [25] and global HRH retention literature, we found that job dissatisfaction was affected by inadequate living and working conditions, inconsistent financial remuneration, and poor support systems. However, we also identified a critical factor underlying these drivers of dissatisfaction-a lack of HCW knowledge of entitlements, policies, procedures, and nationallevel changes to HRH programming, coupled with lack of clarity in many of the policies. This directly translated to many HCWs not accessing their employee rights, not benefitting from advancement opportunities, and not being able to resolve individual HR challenges. Lack of proactive, regular communication of clear and accurate information from the government to $\mathrm{HCWs-combined}$ with the inability of HCWs to obtain updated and accurate information on their own-disempowered and frustrated them. It also fostered the sentiment among HCWs that the government does not care about the welfare of its employees.

To our knowledge, this is the first primary research investigating the $\mathrm{HCW}$ knowledge gap around $\mathrm{HR}$ policies and entitlements and its linkage to HCW job satisfaction and retention. If left unaddressed, this foundational problem threatens to undermine the effectiveness of other incentives and initiatives aimed at reducing rural HCW attrition in Sierra Leone. For example, the government may invest funds to provide additional career advancement scholarships for rural HCWs, but if the change in policy, criteria for candidate selection, and application procedures are not clearly communicated to HCWs, and if there are not effective avenues for HCWs to obtain clarification and information or follow-up on any application issues, the result may be confusion on the ground, perception of poor transparency, fractured implementation, and ultimately a muted effect on retention.

Based on our findings, we propose potential approaches to tackle the $\mathrm{HCW}$ knowledge and communication gaps in Sierra Leone, with the goal of improving $\mathrm{HCW}$ job satisfaction, distribution, retention, and productivity. These are tailored to Sierra Leone's context, but may be applicable to other low- and middle-income countries (LMICs) experiencing similar HCW retention challenges.

First, regular updates and communication could flow from the MOHS to the district health management teams (DHMTs) and health workers, with a feedback loop to enable central monitoring as well as receipt of health worker questions and concerns (Fig. 4). For example, the MOHS HRH Directorate could send a 


\section{Proposed Monthly HRH Two-Way Communication System}

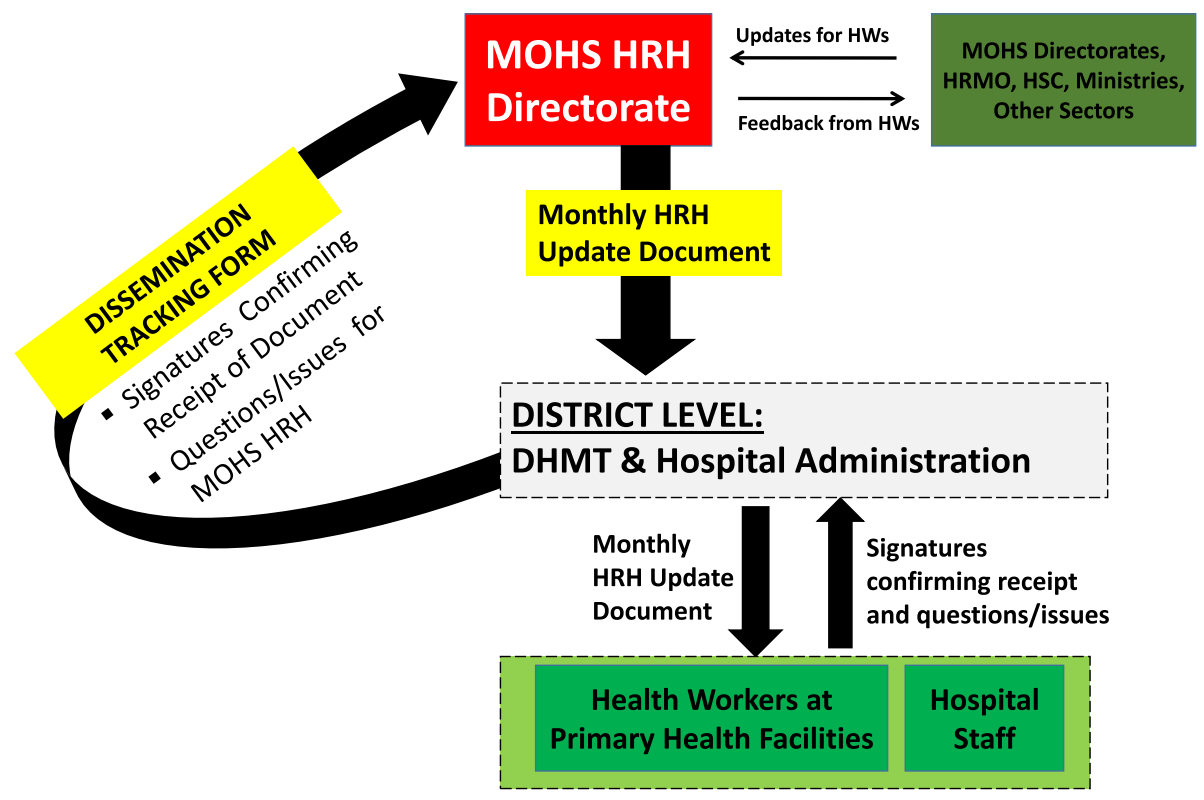

Fig. 4 Potential two-way communication system between the Ministry of Health and health workers. Abbrev. MOHS = Ministry of Health and Sanitation, HRH = Human Resources for Health, DHMT = district health management team, HRMO = Human Resource Management Office, HSC = Health Service Commission

formal, monthly "HRH Update" document to each DHMT to provide to district staff and HCWs. The HCWs and DHMT could communicate back to the MOHS HRH Directorate raising issues and queries.

Second, an HRH Policies, Procedures, and Regulations document could be developed, which articulates in simple language how entitlements and policies in the generic Civil Service Code apply specifically to MOHS employees. The document could be regularly updated to reflect policy changes. This could reduce confusion among HCWs, ensure they follow the correct procedural steps, and provide guidance on what to do if a process has stalled. As an example of the type and format of information that may be useful for HCWs, we created a stepwise flow chart for the civil service absorption process based on our discussions with government agencies (see Additional file 3).

Third, pay statements could provide a full breakdown of the "composite salary" (Fig. 5). This would include all allowances (housing, medical, transport) and all withholdings (social security, taxes), enabling HCWs to fully understand how they are being compensated.

Finally, induction training could be provided for all new entrants into Civil Service and for current HCWs, including explanation of their benefits and national policies. This would ensure that they possess the correct knowledge about all policies and procedures, rules and regulations, and entitlements.

\section{Conclusions}

To improve rural workforce distribution and retention in Sierra Leone and similar country contexts, strong systems must be put in place for two-way communication between government and its HCWs; policies must be formulated with consensus and articulated without ambiguity; and HCWs must be provided with the necessary documentation about policies and procedures for accessing their rights. In Sierra Leone, the gaps in $\mathrm{HCW}$ knowledge and communication have been largely absent from discussions among government, donors, and NGO stakeholders about how to address health workforce challenges.

Global recommendations have been developed by the World Health Organization which serve as the framework for many countries as they consider how to address health workforce mal-distribution and attrition [31-33]. However, these recommendations do not address challenges in health worker knowledge and awareness of entitlements and policies, or the systems for how policies are articulated and communicated from the central government to its health workers. Although rural workforce retention challenges take different forms depending on the country and context, the structural gaps identified in this study likely exist in other LMICs. Our findings suggest that further research is needed in other LMICs to understand this challenge on a broader scale. 


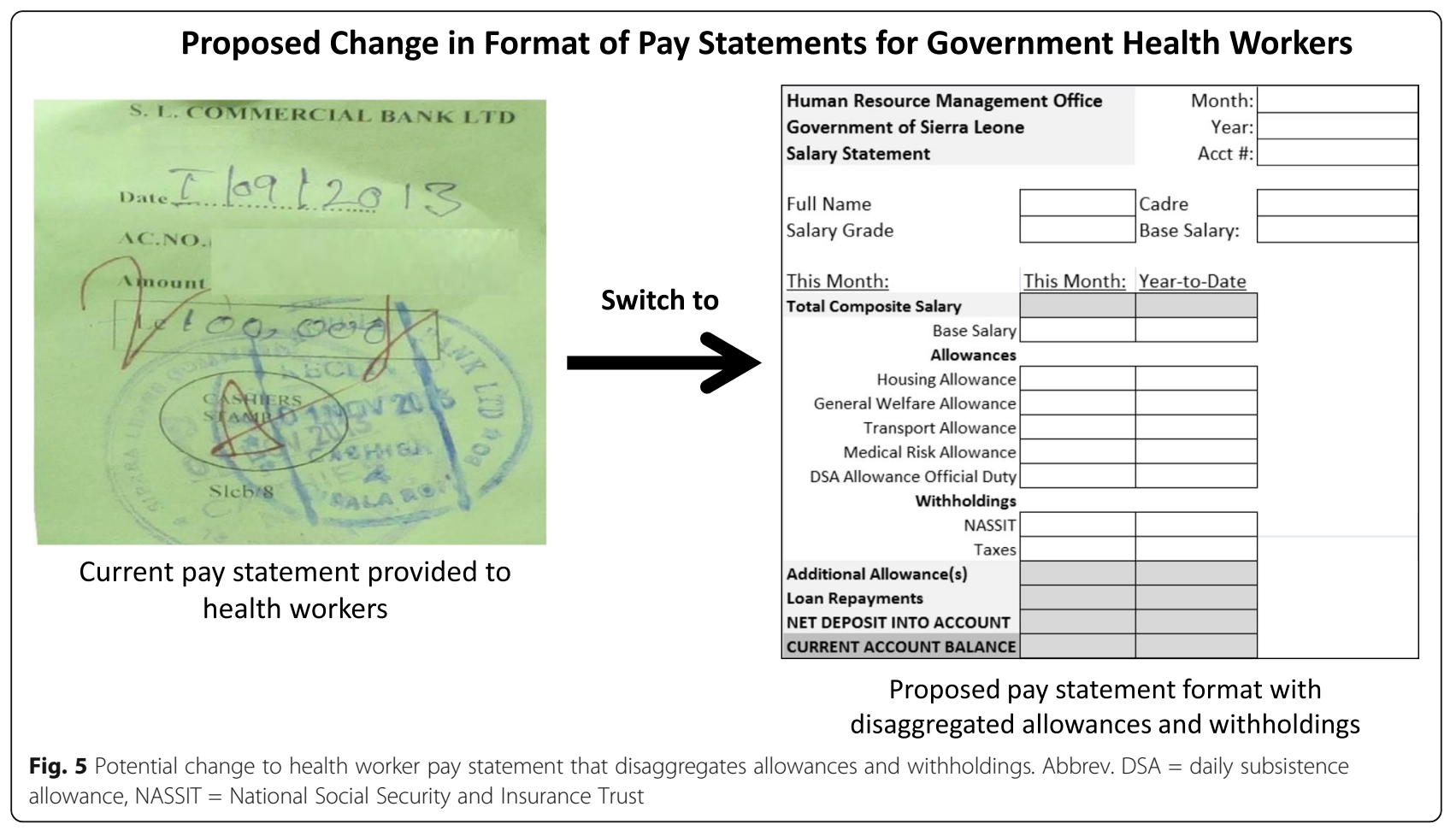

Policymakers should consider addressing this driver of $\mathrm{HCW}$ dissatisfaction and its root causes in global and country-specific recommendations about increasing rural workforce retention. Failure to address and prioritize this key foundational barrier may limit the effectiveness of other initiatives undertaken to improve health workforce retention.

\section{Additional files}

Additional file 1: Sierra Leone's health system. Overview of Sierra Leone's health system. Key background information about the country's health system, including administrative districts and demographics, health facility levels, and cadres and staffing ratios. (PDF $472 \mathrm{~kb}$ )

Additional file 2: Card sort ranking method. Card sort method used to assess health worker priorities. Depiction and description of the card sort method used to measure health worker prioritization of factors affecting job satisfaction. (PDF $658 \mathrm{~kb}$ )

Additional file 3: Flowchart for absorption process. Flowchart showing the process for health worker absorption into Sierra Leone's civil service. Flowchart showing the stepwise process for healthcare workers to be absorbed into the civil service and onto the government payroll. This was created by study investigators and is an example of the type and format of information that can more effectively inform healthcare workers about procedures to access their employee rights. (PDF $581 \mathrm{~kb}$ )

\section{Abbreviations}

CHA: Community health assistant; $\mathrm{CHO}$ : Community health officer; DHMT: District health management team; HCW: Healthcare worker; HR: Human resources; HRH: Human Resources for Health; HRMO: Human Resource Management Office; LMIC: Low- and middle-income country; MCHA: Maternal child health aide; MOHS: Ministry of Health and Sanitation; SECHN: State-enrolled community health nurse; SRN: State-registered nurse

\section{Acknowledgements}

We are grateful to the many health workers in Sierra Leone who shared their stories and experiences with us. We would like to thank Emmanuel Konjoh and his staff at the Health and Social Development Association (HASDA) for helping facilitate implementation of this study in Sierra Leone, as well as the Ministry of Health and Sanitation for their high-level support. Faculty and staff at the University of Washington's School of Public Health provided invaluable technical support, especially Clarke Speed, Amy Hagopian, James Pfeiffer, and Jennifer Tee.

\section{Funding}

This study had no dedicated funding. It was conducted as operational research in Sierra Leone to help inform policies and program initiatives to address health workforce retention challenges.

\section{Availability of data and materials}

The datasets used and analyzed during the current study are available from the corresponding author on reasonable request.

\section{Authors' contributions}

VN designed and implemented the study, performed statistical analysis, interpreted results, worked with in-country stakeholders to utilize the study's findings, and drafted the manuscript. GG contributed to the study design, ensured that it fit local context, and helped facilitate in-country implementation and dissemination. GO and GJ-S guided and participated in the study design, contributed in its implementation, provided their technical expertise in the subject matter, and edited draft versions of the manuscript. All authors read and approved the final manuscript.

\section{Ethics approval and consent to participate}

This study was approved by the University of Washington Institutional Review Board (Seattle, Washington USA) and Sierra Leone Ethics and Scientific Review Committee (Freetown, Sierra Leone). Informed written consent was obtained from all study participants.

\section{Consent for publication}

Not applicable.

\section{Competing interests}

The authors declare that they have no competing interests. 


\section{Publisher's Note}

Springer Nature remains neutral with regard to jurisdictional claims in published maps and institutional affiliations.

\section{Author details}

'Department of Global Health, University of Washington, Seattle, United States of America. ${ }^{2}$ College of Medicine and Applied Health Sciences, University of Sierra Leone, Freetown, Sierra Leone.

Received: 27 April 2018 Accepted: 26 August 2018

Published online: 24 September 2018

\section{References}

1. International Labor Organization (ILO). World social protection report 20172019: universal social protection to achieve the Sustainable Development Goals: ILO; 2017. p. 101-17. Accessed from http://www.lo.org/global/ publications/books/WCMS_604882/lang\%2D\%2Den/index.htm

2. World Health Organization (WHO). Global Strategy on Human Resources for Health: Workforce 2030: WHO; 2016. Accessed from http://www.who.int/ hrh/resources/globstrathrh-2030/en/

3. Dussault G, Franceschini MC. Not enough there, too many here: understanding geographical imbalances in the distribution of the health workforce. Hum Resour Health. 2006;4(1):12.

4. Willis-Shattuck M, Bidwell P, Thomas S, Wyness L, Blaauw D, Ditlopo P. Motivation and retention of health workers in developing countries: a systematic review. BMC Health Serv Res. 2008:8:247.

5. Lemiere C, Herbst C, Jahanshahi N, Smith E, Soucat A. Reducing geographical imbalances of health workers in sub-Saharan Africa: a labor market perspective on what works, what does not, and why, vol. 209. Washington DC: World Bank Publications; 2010.

6. Lehmann U, Dieleman M, Martineau T. Staffing remote rural areas in middle-and low-income countries: a literature review of attraction and retention. BMC Health Serv Res. 2008:8(1):19.

7. World Health Organization (WHO). World Health Statistics 2017: Monitoring Health for the SDGs: WHO; 2017. Accessed from http:/www.who.int/gho/ publications/world_health_statistics/2017/en/

8. United Nations International Children's Emergency Fund (UNICEF). Data: Monitoring the Situation of Children and Women, Sierra Leone: UNICEF; 2016. Accessed from https://data.unicef.org/country/sle/

9. World Health Organization (WHO). Ebola in Sierra Leone: A Slow Start to an Outbreak that Eventually Outpaced All Others: WHO; 2015. Accessed from www.who.int/csr/disease/ebola/one-year-report/sierra-leone/en/

10. World Health Organization (WHO). Cholera in Sierra Leone: the case study of an outbreak: WHO; 2012. Accessed from www.who.int/features/2012/ cholera_sierra_leone/en/

11. Sierra Leone Ministry of Health and Sanitation (MoHS). National health sector strategic plan, 2017-2021. Freetown, Sierra Leone; 2017.

12. Sierra Leone Ministry of Health and Sanitation (MoHS). National Health Training Plan, 2013-2023. Freetown, Sierra Leone; 2013.

13. MacKinnon J, MacLaren B. Human resources for health challenges in fragile states: evidence from Sierra Leone, South Sudan and Zimbabwe. Ottawa, Canada: North-South Institute; 2012.

14. Cummings E. Health workers define key challenges to job motivation, performance, and quality of care: evidence from two districts in Sierra Leone. Report of Sierra Leone health and biomedical research association, 5th annual symposium. Freetown, Sierra Leone: Concern Worldwide; 2012.

15. Witter S, Wurie H, Bertone MP. The free health care initiative: how has it affected health workers in Sierra Leone? Health Policy Plan. 2015;31(1):1-9.

16. World Health Organization (WHO). Global Health Observatory: density of physicians by country: WHO; 2017. Accessed from http://www.who.int/gho/ health_workforce/physicians density/en/

17. Sierra Leone Ministry of Health and Sanitation (MoHS). Human Resources for Health (HRH) Strategy 2017-2021. Freetown, Sierra Leone; 2017.

18. Mathauer I, Imhoff I. Health worker motivation in Africa: the role of nonfinancial incentives and human resource management tools. Hum Resour Health. 2006;4(1):24.

19. Zurn P, Dolea C, Stilwell B. Nurse retention and recruitment: developing a motivated workforce. International Council of Nurses, World Health Organization; 2005.

20. Dieleman M, Kleinau E. Factors influencing retention, job satisfaction, and motivation among Jordanian health workers. Ann GlobHealth. 2017;83(1):51-2.
21. Bonenberger $M$, Aikins $M$, Akweongo $P$, Wyss $K$. The effects of health worker motivation and job satisfaction on turnover intention in Ghana: a crosssectional study. Hum Resour Health. 2014;12(1):43.

22. Smitz MF, Witter S, Lemiere C, Eozenou PH, Lievens T, Zaman RU, et al. Understanding health workers' job preferences to improve rural retention in Timor-Leste: findings from a discrete choice experiment. PLoS One. 2016; 11(11):e0165940.

23. Ojakaa $D$, Olango $S$, Jarvis J. Factors affecting motivation and retention of primary health care workers in three disparate regions in Kenya. Hum Resour Health. 2014;12(1):33.

24. Dieleman M, Cuong PV, Martineau T. Identifying factors for job motivation of rural health workers in North Viet Nam. Hum Resour Health. 2003;1 (1):10.

25. Wurie HR, Samai M, Witter S. Retention of health workers in rural Sierra Leone: findings from life histories. Hum Resour Health. 2016;14(1):3.

26. Hagopian A, Zuyderduin A, Kyobutungi N, Yumkella F. Job satisfaction and morale in the Ugandan health workforce. Health Aff. 2009;28(5):w863-75.

27. Braun V, Clarke V. Using thematic analysis in psychology. Qual Res Psychol. 2006;3(2):77-101.

28. Vaismoradi $\mathrm{M}$, Turunen $\mathrm{H}$, Bondas $\mathrm{T}$. Content analysis and thematic analysis: implications for conducting a qualitative descriptive study. Nurs Health Sci. 2013;15(3):398-405.

29. Jick TD. Mixing qualitative and quantitative methods: triangulation in action. Adm Sci Q. 1979;24(4):602-11.

30. Sierra Leone Ministry of Health and Sanitation (MOHS). Civil service code of regulations, and rules. Freetown, Sierra Leone; 2004.

31. World Health Organization (WHO). Increasing access to health workers in remote and rural areas through improved retention: global policy recommendations. WHO; 2010.www.who.int/hrh/retention/guidelines/en/.

32. Buchan J, Couper ID, Tangcharoensathien V, Thepannya K, Jaskiewicz W, Perfilieva G, Dolea C. Early implementation of WHO recommendations for the retention of health workers in remote and rural areas. Bull World Health Organ. 2013;91:834-40

33. Grobler L, Marais BJ, Mabunda SA, Marindi PN, Reuter H, Volmink J. Interventions for increasing the proportion of health professionals practising in rural and other underserved areas. Cochrane Database Syst Rev. 2009;1(1): CD005314.

Ready to submit your research? Choose BMC and benefit from:

- fast, convenient online submission

- thorough peer review by experienced researchers in your field

- rapid publication on acceptance

- support for research data, including large and complex data types

- gold Open Access which fosters wider collaboration and increased citations

- maximum visibility for your research: over $100 \mathrm{M}$ website views per year

At BMC, research is always in progress.

Learn more biomedcentral.com/submissions 